\title{
Global thermospheric disturbances induced by a solar flare: a modeling study
}

\author{
Huijun Le ${ }^{1,2^{*}}$, Zhipeng Ren ${ }^{1,2}$, Libo Liu ${ }^{1,2}$, Yiding Chen ${ }^{1,2}$ and Hui Zhang ${ }^{1,2}$
}

\begin{abstract}
This study focuses on the global thermosphere disturbances during a solar flare by a theoretical model of thermosphere and ionosphere. The simulated results show significant enhancements in thermospheric density and temperature in dayside hemisphere. The greatest thermospheric response occurs at the subsolar point, which shows the important effect of solar zenith angle. The results show that there are also significant enhancements in nightside hemisphere. The sudden heating due to the solar flare disturbs the global thermosphere circulation, which results in the significant change in horizontal wind. There is a significant convergence process to the antisolar point and thus the strong disturbances in the nightside occur at the antisolar point. The peak enhancements of the neutral density around antisolar point occur at about $4 \mathrm{~h}$ after solar flare onset. The simulated results show that thermospheric response to a solar flare mainly depends on the total integrated energy into the thermosphere, not the peak value of EUV flux. The simulated results are basically consistent with the observations derived from the CHAMP satellite, which verified the results of this modeling study.
\end{abstract}

Keywords: Solar flare; Thermospheric disturbance; lonosphere and thermosphere model

\section{Background}

Solar flares produce great enhancements in extreme ultaviolet (EUV) and X-ray radiations, which cause sudden and intense disturbances in the Earth's upper atmosphere. Ionospheric effects of solar flares, or sudden ionospheric disturbances (SID), have been studied since 1960s owing to their effects on radio communications and navigation systems. Most previous studies related to solar flares have so far focused on the ionospheric responses (e.g., Afraimovich 2000; Leonovich et al. 2002; Liu et al. 2004, 2006; Mahajan et al. 2010; Tsurutani 2005; Wan et al. 2005; Zhang et al. 2002; Zhang and Xiao 2005; Le et al. 2007, 2011, 2013; Liu et al. 2011). Compared to the research on the ionospheric responses to solar flares, the study on the thermospheric responses to solar flares is relatively scarce. It may be due to the much less observation of the thermosphere than that of the ionosphere. The observations of the terrestrial effects of solar flares have recently been extended to the neutral atmosphere. The neutral density data near $400 \mathrm{~km}$ has

\footnotetext{
* Correspondence: lehj@mail.iggcas.ac.cn

'Key Laboratory of Earth and Planetary Physics, Institute of Geology and Geophysics, Chinese Academy of Sciences, Beijing, China

${ }^{2}$ Beijing National Observatory of Space Environment, Institute of Geology and Geophysics, Chinese Academy of Sciences, Beijing, China
}

been obtained from accelerometer measurements of nongravitational accelerations on the Challenging Minisatellite Payload (CHAMP) and the Gravity Recovery and Climate Experiment (GRACE) satellites.

Some studies have been performed to quantify the thermospheric response to flares based on the neutral density data from the CHAMP and GRACE satellites (e.g., Forbes et al. 2005; Sutton et al. 2006; Liu et al. 2007; Pawlowski and Ridley 2008, 2009, 2011). These studies show that in addition to the great disturbances in the ionosphere, solar flares can also induce significant responses in the thermosphere. Sutton et al. (2006) reported the first measurements of the thermosphere density response to two great flare events on 28 October 2003 (X17) and 4 November 2003 (X28). They found the thermosphere density increases associated with the flares are about $50 \%$ to $60 \%$ and $35 \%$ to $45 \%$, respectively, at low to mid-latitudes. Liu et al. (2007) examined both the thermospheric and ionospheric responses to the solar flare on 28 October 2003 by using measurements from the CHAMP satellite. Pawlowski and Ridley (2008) simulated the thermospheric responses to the solar flare on 28 October 2003 using the Global IonosphereThermosphere Model (GITM). Their results show that 


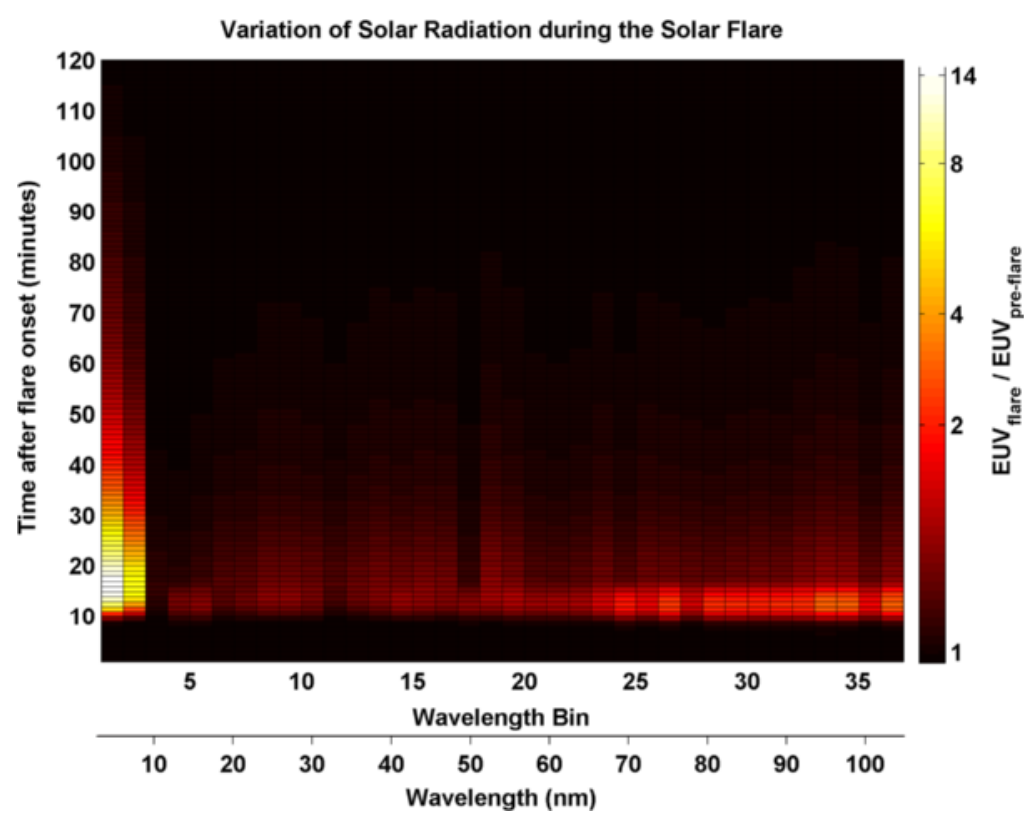

Figure 1 Solar EUV relative variation as a function of wavelength bin and time after flare onset. The relative variation refers to the ratio of solar EUV flux after solar flare to that before the solar flare. The wavelength bins of 1 to 37 correspond to wavelength 0 to $105 \mathrm{~nm}$.
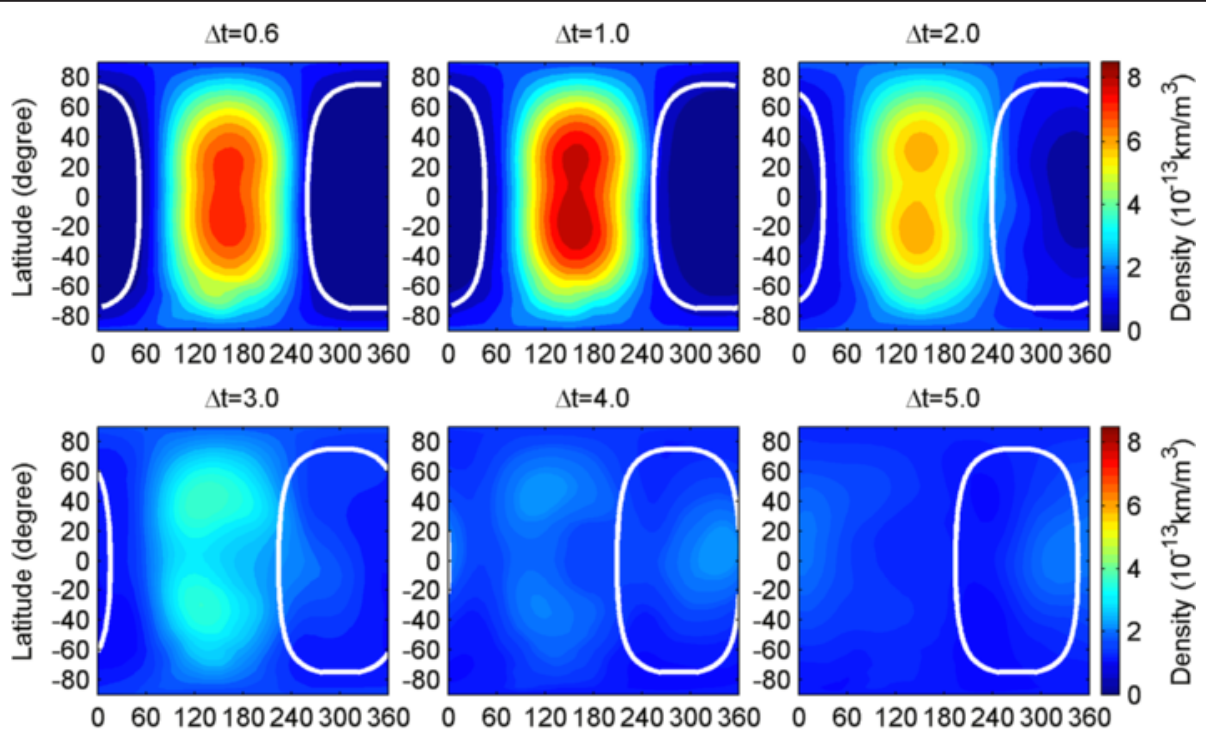

$\Delta \mathrm{t}=8.0$

$\Delta \mathrm{t}=11.0$

$\Delta t=14.0$
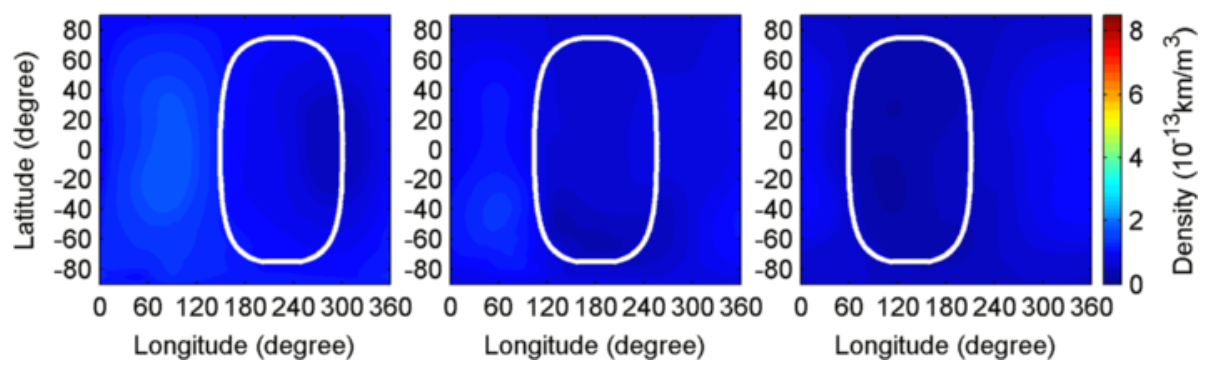

Figure $\mathbf{2}$ Simulated global variations in neutral density at $\mathbf{4 0 0} \mathbf{~ k m}$ at different times after the solar flare. The solid lines in each panel indicate the solar terminator at an altitude of $200 \mathrm{~km}$. 
the thermospheric density at $400 \mathrm{~km}$ can increase by as much as $14.6 \%$ in about $2 \mathrm{~h}$ and takes $12 \mathrm{~h}$ to return back to a normal state. Qian et al. (2010) also investigated the ionosphere and the thermosphere response to the X17 solar flare on 28 October 2003 by the thermosphere-ionosphere-mesosphere electrodynamics general circulation model (TIME-GCM). The results also show the significant thermospheric disturbances including about a maximum increase of $20 \%$ in neutral density at altitude of $400 \mathrm{~km}$.

As mentioned above, there are many studies focusing on ionospheric and thermospheric responses to the great X17 solar flare on 28 October 2003. How about a weaker flare's effect on the thermosphere? Le et al. (2012) statistically analyzed the neutral density variation for all X-class solar flares during 2001 to 2006 based on the density data derived from accelerometers on the CHAMP and GRACE satellites. The observed results show the density response for $\mathrm{X} 1$ to $\mathrm{X} 5$ flares falls within the noise level in the thermosphere, but there is significant neutral density response for $\mathrm{X} 5$ and stronger flares, with an average enhancement of $10 \% \sim 13 \%$ in neutral density at the altitude of $400 \mathrm{~km}$ at mid-low latitudes within about $4 \mathrm{~h}$ after solar flare onset. In this study, we would explore the global thermospheric disturbances induced by a solar flare with magnitude of X5 and the transport process of energy by using the Global Coupled IonosphereThermosphere-Electrodynamics Model, developed by the Institute of Geology and Geophysics, Chinese Academy of Sciences (GCITEM).

\section{Methods}

\section{GCITEM model introduction}

The model employed in this study is the GCITEM model (Ren et al. 2009). It is a new global 3-D self-consistent model of the ionosphere and thermosphere including electrodynamics. This new model self-consistently calculates the time-dependent 3-D structures of the main thermospheric and ionospheric parameters in the height range from 90 to $600 \mathrm{~km}$, including neutral number density of the major species $\mathrm{O}_{2}, \mathrm{~N}_{2}$, and $\mathrm{O}$ and the minor species $\mathrm{N}(2 \mathrm{D}), \mathrm{N}(4 \mathrm{~S}), \mathrm{NO}, \mathrm{He}$, and Ar; ion number densities of
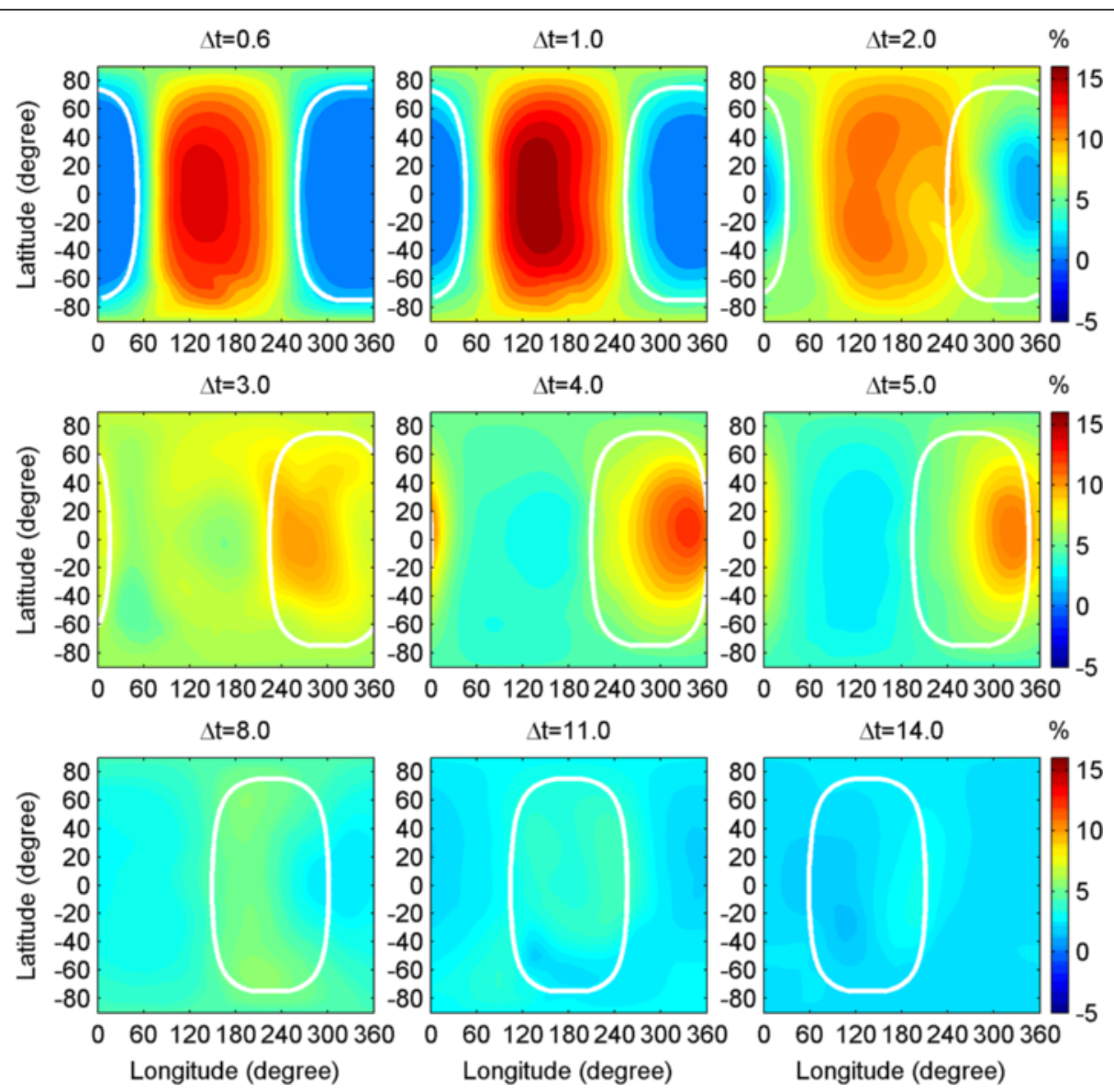

Figure 3 Percentage variations in neutral density at $\mathbf{4 0 0} \mathbf{~ k m}$ at different times after the solar flare. The solid lines in each panel indicate solar terminator at an altitude of $200 \mathrm{~km}$. 
$\mathrm{O}^{+}, \mathrm{O}_{2}^{+}, \mathrm{N}_{2}^{+}, \mathrm{NO}^{+}, \mathrm{N}^{+}$, and electron; neutral, electron, and ion temperature; and neutral wind vectors. The ionospheric electric fields in the mid and low latitudes can also be self-consistently calculated. The model is based on the hydrostatic assumption. It is a full $3-\mathrm{D}$ code with $5^{\circ}$ latitude by $7.5^{\circ}$ longitude grids in a spherical geomagnetic coordinate system. The vertical grid spacing is about $3 \mathrm{~km}$ in the lower thermosphere and about $30 \mathrm{~km}$ in the upper thermosphere. This model is solved by a time-stepping finite difference procedure, with a time step of $2 \sim 5 \mathrm{~min}$. The horizontal difference procedure uses explicit numerical method. To get the rapid vertical molecular diffusion, the vertical difference procedure uses implicit numerical method. The GCITEM model can simulate the ionosphere-thermosphere system in a realistic geomagnetic field. This is important in the research of the couple between the neutrals and ions, and the anomaly of the ionospheric and thermospheric spatial-temporal variations. GCITEM-IGGCAS can simulate the complex chemistry, thermodynamics, dynamics, and electrodynamics of the coupled ionosphere-thermosphere system.
Thus, it is an effective platform to simulate solar flare effects on the thermosphere and ionosphere. In this study, we focus on the thermospheric responses to a solar flare.

\section{Simulations}

In this study, we modeled the thermospheric responses to an X5 solar flare. The solar EUV variation during an about X5 solar flare on 6 April 2001 is used in the simulations. The EUV variation during the solar flare is calculated by the Flare Irradiance Spectral Model (FISM). The ratio of EUV flux during the flare to that before the flare $\left(E U V_{\text {flare }} / E U V_{\text {pre-flare }}\right)$ as a function of UT time and wavelength is shown in Figure 1. The FISM model is an empirical model that estimates the solar irradiance at wavelengths from 0.1 to $190 \mathrm{~nm}$ at $1-\mathrm{nm}$ resolution. The long wavelength channel on the GOES X-ray sensor (XRS) provides a value of the 0.1 to $0.8 \mathrm{~nm}$ irradiance. The GOES XRS values are currently the only near realtime data that are given on-time scales short enough to represent various changes in irradiance due to solar flares; the GOES 0.1 to $0.8 \mathrm{~nm}$ fluxes are used as the
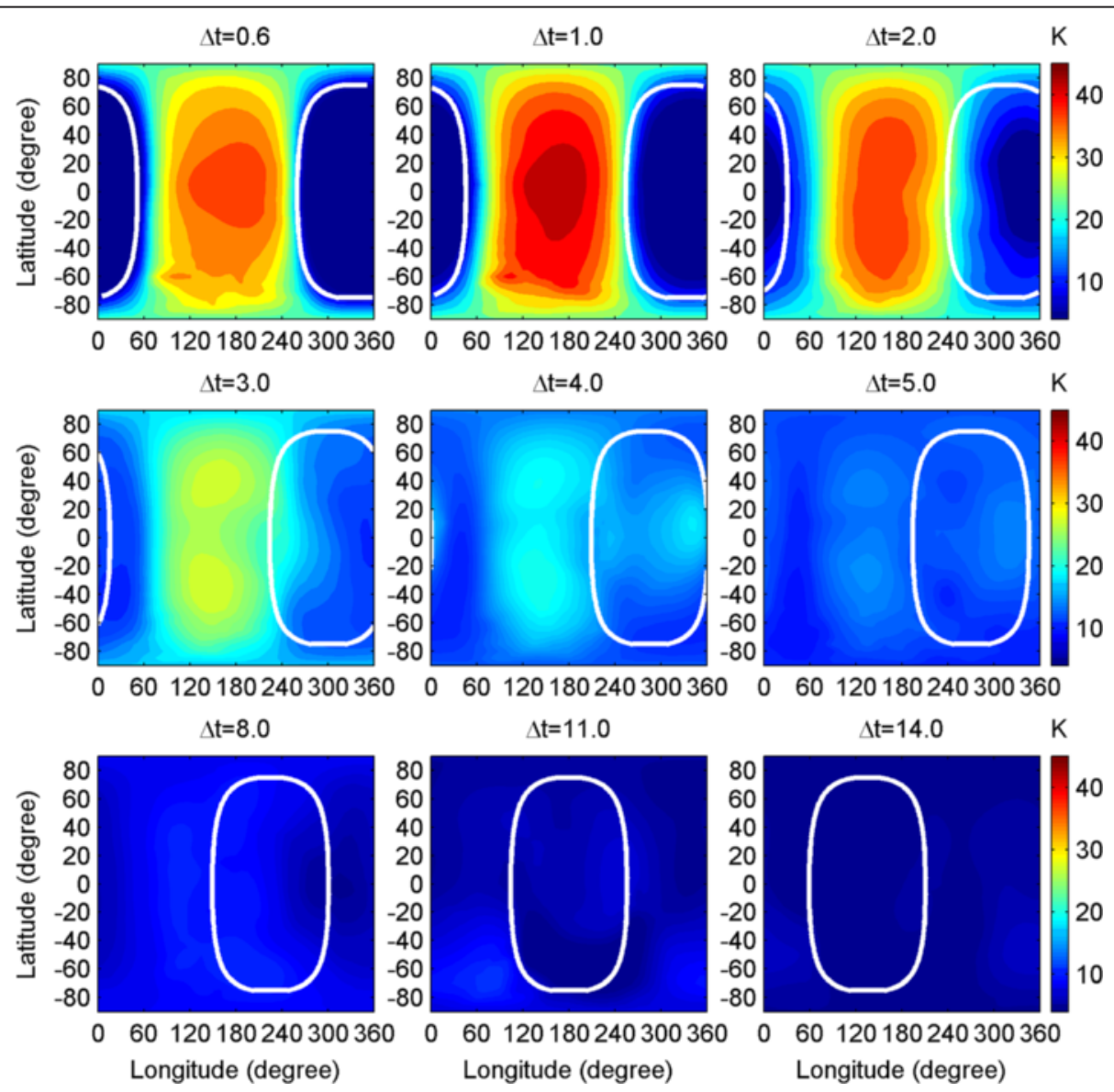

Figure 4 Simulated global variations in neutral temperature at $\mathbf{4 0 0} \mathbf{~ k m}$ at different times after the solar flare. The solid lines in each panel indicate solar terminator at an altitude of $200 \mathrm{~km}$. 
short-term solar flare proxy for FISM. The model has a high temporal resolution of $60 \mathrm{~s}$ to model EUV variations due to solar flares (for details please see Chamberlin et al. 2007, 2008).

The reference simulation is carried out on 6 April (day of year $=96$ ) with the median solar activity condition $(\mathrm{F} 10.7=140.0)$. Then the solar EUV variation during the solar flare is embedded in the GCITEM model to model the thermospheric responses to the solar flare. The time step in the simulations is $2 \mathrm{~min}$. The solar flare onset is set at 0100 UT. The differences of neutral density, neutral temperature, and horizontal wind between the two simulations are calculated to represent the responses of density, temperature, and wind.

\section{Results and discussion}

The absolute change of neutral density between the flare simulation and the reference simulation is calculated. $\Delta t$ is the time after the solar flare onset. The absolute change of neutral density at $400 \mathrm{~km}$ at different $\Delta \mathrm{t}$ from 0.6 to $14 \mathrm{~h}$ is illustrated in Figure 2. The results show significant increases in the whole dayside hemisphere including high latitudes and polar region. The largest increase occurs at the subsolar point. The neutral density enhancement is larger at the region with smaller solar zenith angle, which shows the significant effect of solar zenith angle on the thermospheric response to a solar flare. The results also show that the thermospheric density disturbances mainly focus on the sunlight region at the initial stage $(\Delta t<1 \mathrm{~h})$; then the disturbance region gradually extends to the nightside with time. The results also show that the peak enhancement gradually moves from low latitudes to higher latitudes. For example, the peak enhancement in the northern hemisphere moves from $20^{\circ} \mathrm{N}$ at $\Delta \mathrm{t}=0.6 \mathrm{~h}$ to $40^{\circ} \mathrm{N}$ at $\Delta \mathrm{t}=3 \mathrm{~h}$. To better show the change of neutral density in both the dayside and the nightside, the percentage changes $(\Delta \mathrm{Nn})$ at different times are plotted in Figure 3. We can find significant increases in the dayside with a peak of approximately $15 \%$ at the subsolar point. We also can find significant disturbances in the nightside and later at $\Delta t=2$. The peak enhancement at the antisolar point reaches as large as $12 \%$, just a little smaller than that at the subsolar point.

Figure 4 illustrates the change of neutral temperature $(\Delta T \mathrm{n})$ at $400 \mathrm{~km}$ between the flare simulation and the

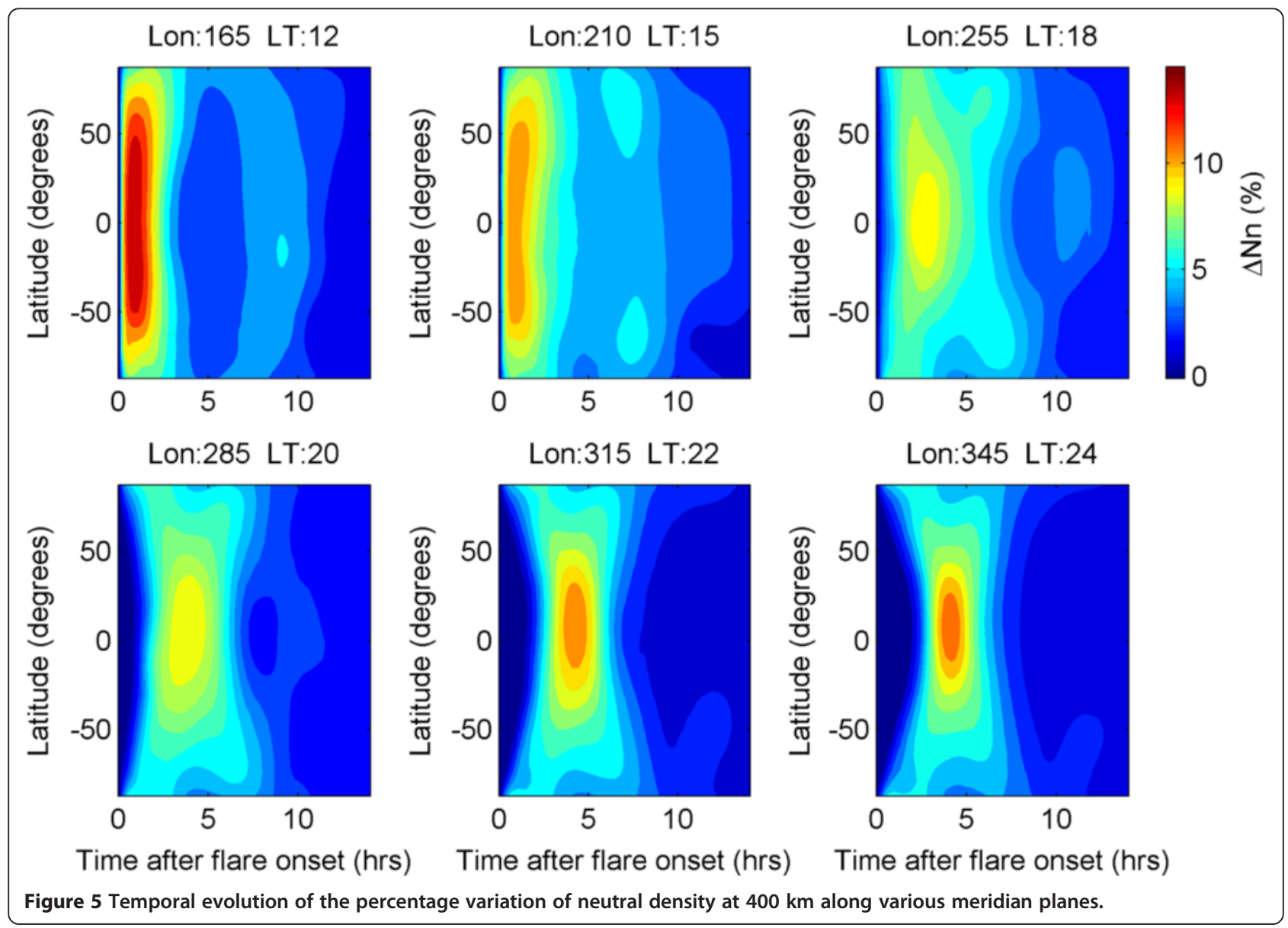


reference simulation. The results show that the change in neutral temperature has similar variations with that of the neutral density. There is a peak increase of about $45 \mathrm{~K}$ in the dayside and about $19 \mathrm{~K}$ in the nightside. In the thermosphere, the primary source of the energy going to the neutrals is solar EUV radiation; at the higher latitudes, the Joule heating becomes dominant at times. During a solar flare, the enhanced solar EUV radiation causes the additional heating of the thermosphere gas (Schunk and Nagy 2000), which results in increase in neutral temperature. The increase in neutral temperature would then alter the scale height of the neutral height, which causes increase in the neutral density at a fixed height like $400 \mathrm{~km}$ as shown in Figure 2; that is, heating below a specific altitude causes the density enhancement at the altitude and above.

The temporal evolution of the percentage changes of neutral density at $400 \mathrm{~km}$ along various meridian planes from dayside to nightside is illustrated in Figure 5. The solar flare onset is set at 0100 UT. So the subsolar point when the flare erupts is in the meridian plane $165^{\circ} \mathrm{E}$ where the time is at $1200 \mathrm{LT}$. the corresponding antisolar point lies in the meridian plane $345^{\circ} \mathrm{E}$ where the time is at 2400 LT. The results show that the thermospheric density responses to the solar flare are synchronous for all latitudes in the dayside because all latitudes are in the sunlight region. For dayside region like the meridian planes $165^{\circ} \mathrm{E}$ (12 LT) and $210^{\circ} \mathrm{E}$ (15 LT), the peak enhancement occurs at about $0.9 \mathrm{~h}$ after the flare onset. However, for the dusk region (18 LT), the peak enhancement occurs later, at approximately $2.5 \mathrm{~h}$ after the flare onset. As for the nightside, the density disturbance is not synchronous for different latitudes. The polar region and high latitudes respond to the solar flare earliest because the altitude of $200 \mathrm{~km}$ and above is still in the sunlight. For other latitudes, the disturbance appears later at the lower latitudes. The temporal evolution of the changes of neutral temperature at $400 \mathrm{~km}$ along various meridian planes from dayside to nightside is illustrated in Figure 6. As mentioned above, the density increases are mainly due to the increase in neutral temperature. Thus, we can find similar variations in neutral temperature with the neutral density variations. For the dayside, the peak enhancement of neutral temperature occurs around the subsolar point at about $0.9 \mathrm{~h}$ after the flare onset. For the nightside, the peak

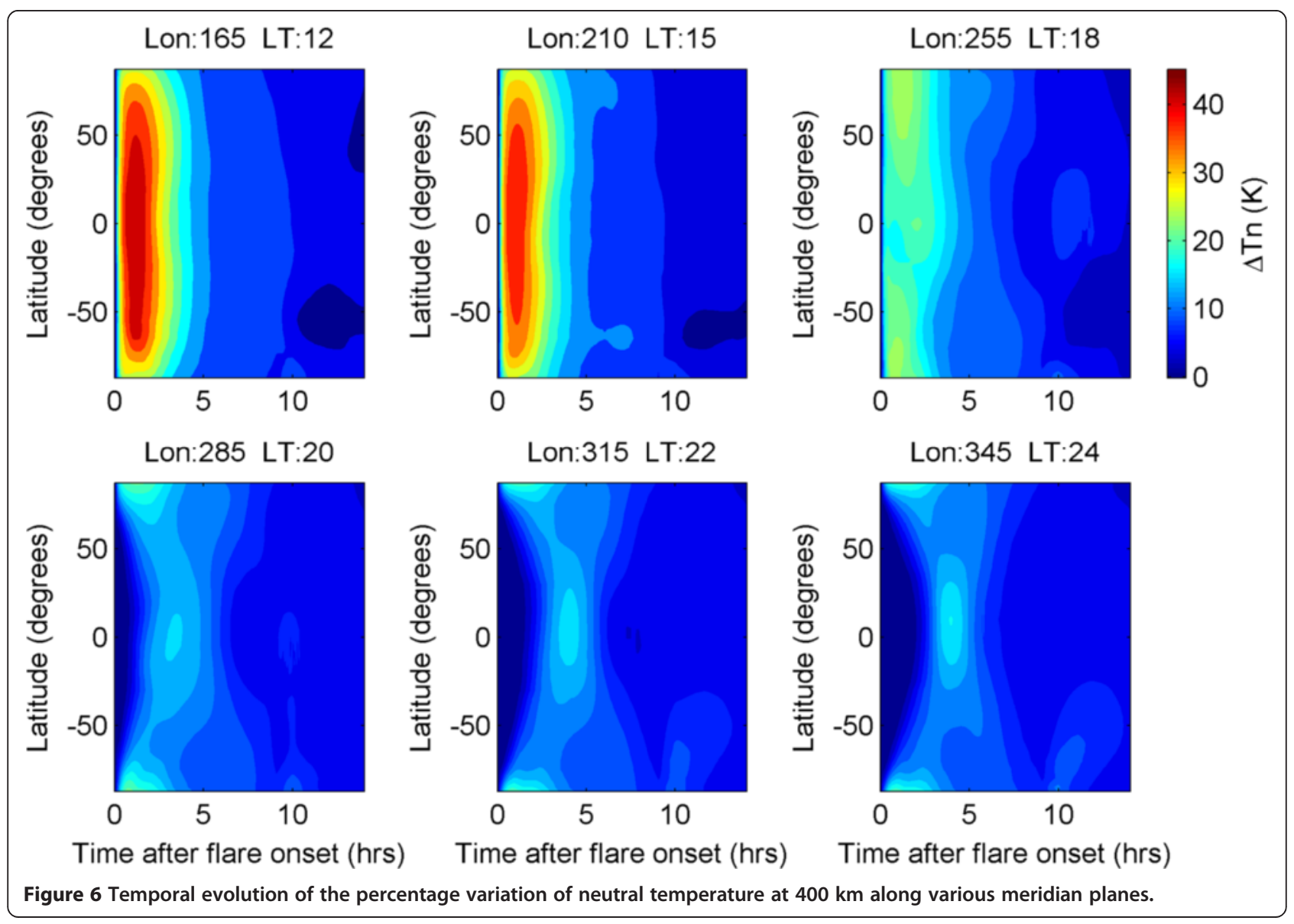


enhancement of neutral temperature occurs around the antisolar point at about $4.0 \mathrm{~h}$ after the flare onset.

As mentioned above, there are significant disturbances induced by the solar flare in both the dayside and the nightside. Figure 7 illustrates the temporal variation of thermospheric average disturbances in the dayside and in the nightside. Here we define the dayside as being solar zenith angles less than $30^{\circ}$, while the nightside is defined as solar zenith angles larger than $150^{\circ}$. The results show that after reaching the peak at $\Delta \mathrm{t} \approx 0.9 \mathrm{~h}$, the disturbances in the dayside do not decay gradually with time but appears as a second peak at $\Delta \mathrm{t} \approx 8 \mathrm{~h}$. The nightside disturbances also show a second peak at $\Delta \mathrm{t} \approx 12.5 \mathrm{~h}$ after the first peak at $\Delta t \approx 4 \mathrm{~h}$. In addition, Figure 7 shows that there is the similar but weaker perturbation in the variation of neutral temperature compared to that of neutral density. The solar flare may excite atmospheric waves, which transports the disturbed energy in the dayside to the nightside and then disturbs the thermospheric atmosphere in the nightside. The global wind changes caused by the solar flare heating disturb the global thermospheric atmosphere, which is also an important factor for the dayside and the nightside disturbances in the neutral density. In the following, we further show the global disturbances in the neutral wind and density.

The absolute change of horizontal wind between the flare simulation and the reference simulation is also calculated. The variations in horizontal wind at an altitude of $400 \mathrm{~km}$ at different times after the solar flare onset are illustrated in Figure 8. The corresponding change in neutral density is also plotted the figure. To better understand the thermospheric behaviors, the background thermospheric density and horizontal wind are plotted in Figure 9. The neutral density has two peaks at latitudes of about $\pm 25^{\circ}$, which is known as equatorial mass anomaly (EMA). The background horizontal wind at the altitude of $400 \mathrm{~km}$ has the maximum value of about $300 \mathrm{~m} / \mathrm{s}$. The results show the significant change in global horizontal wind. In the initial stage of solar flare $(\Delta t=0.6 \mathrm{~h})$, we can find the evident change of horizontal wind in the dayside with the
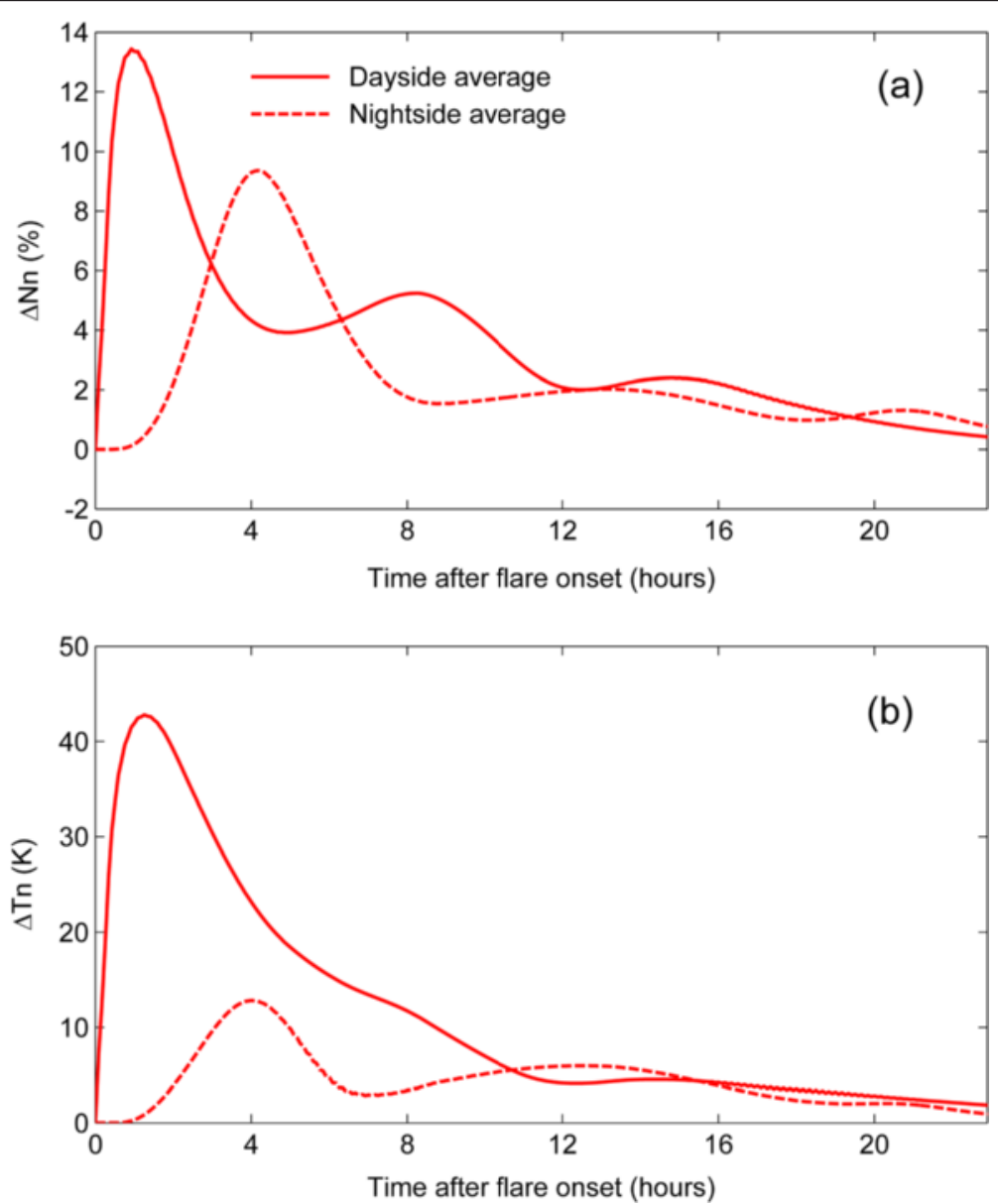

Figure 7 Temporal evolution of dayside average and nightside average responses to the solar flare. Neutral density (a) and neutral temperature (b). 


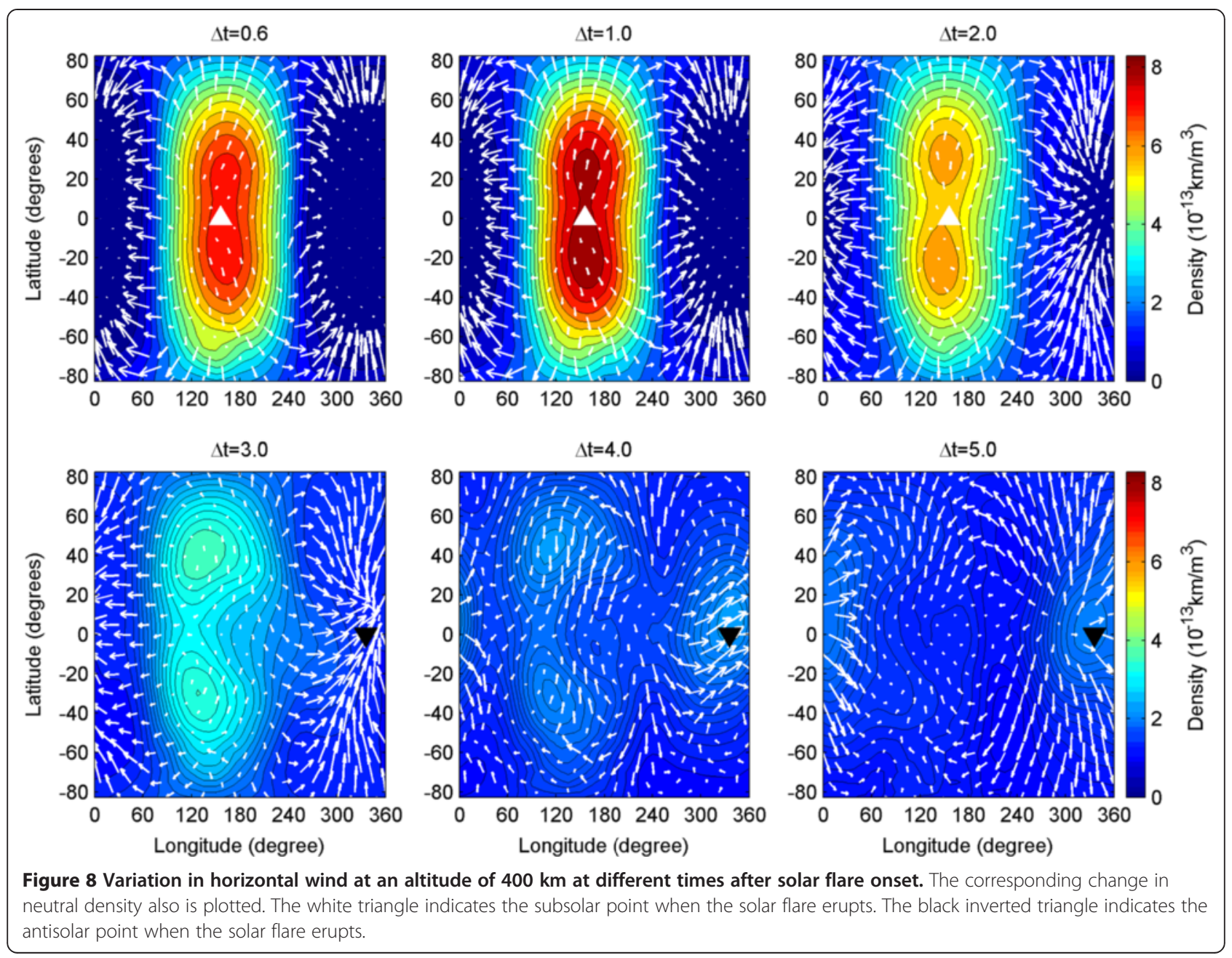

minimum at the subsolar point and the maximum around the solar terminator. The enhanced solar EUV flux heats the thermosphere gas and then the thermosphere expands from low altitudes to higher altitudes and from dayside to nightside. As shown in Figure 8, the place of peak enhancement moves from the subsolar point to higher latitudes, which is driven by the horizontal wind. The gradient of heating rate is largest in the solar terminator line. Thus, the change of the horizontal wind can be found to be largest in the solar terminator. As shown in Figure 9, there is significant neutral wind from dayside to nightside due to the heating pressure from the solar radiation heating in the dayside. The enhanced solar radiation strengthens such a global circulation. Therefore, we can see from Figures 8 and 9 that both the background neutral wind and the change in neutral wind have significant convergence process from high latitudes to low latitudes and from dayside to nightside. The global thermospheric circulation causes the significant variation in the nightside and also affects the variation in the dayside.
The simulations were carried out around March equinox. The subsolar point locates around the equator, so the simulated results show a symmetric thermospheric disturbance in the southern and northern hemispheres. If the solar flare occurs in other seasons, we can find the seasonal difference in the thermospheric responses. Figure 10 illustrates the simulated results in July solstice and in December solstice. The results also show significant enhancements in neutral density in the dayside with a peak at subsolar point, as well as enhancements in the nightside with a peak at antisolar point. For July solstice, the significant disturbances in the nightside occur in the southern hemisphere. For December, the significant disturbances in the nightside occur in the northern hemisphere. We can also find the significant disturbances in thermospheric global circulation both in July solstice and in December solstice. There is a significant convergence to the antisolar point around $\Delta \mathrm{t}=3 \mathrm{~h}$ for both July solstice and December solstice. 


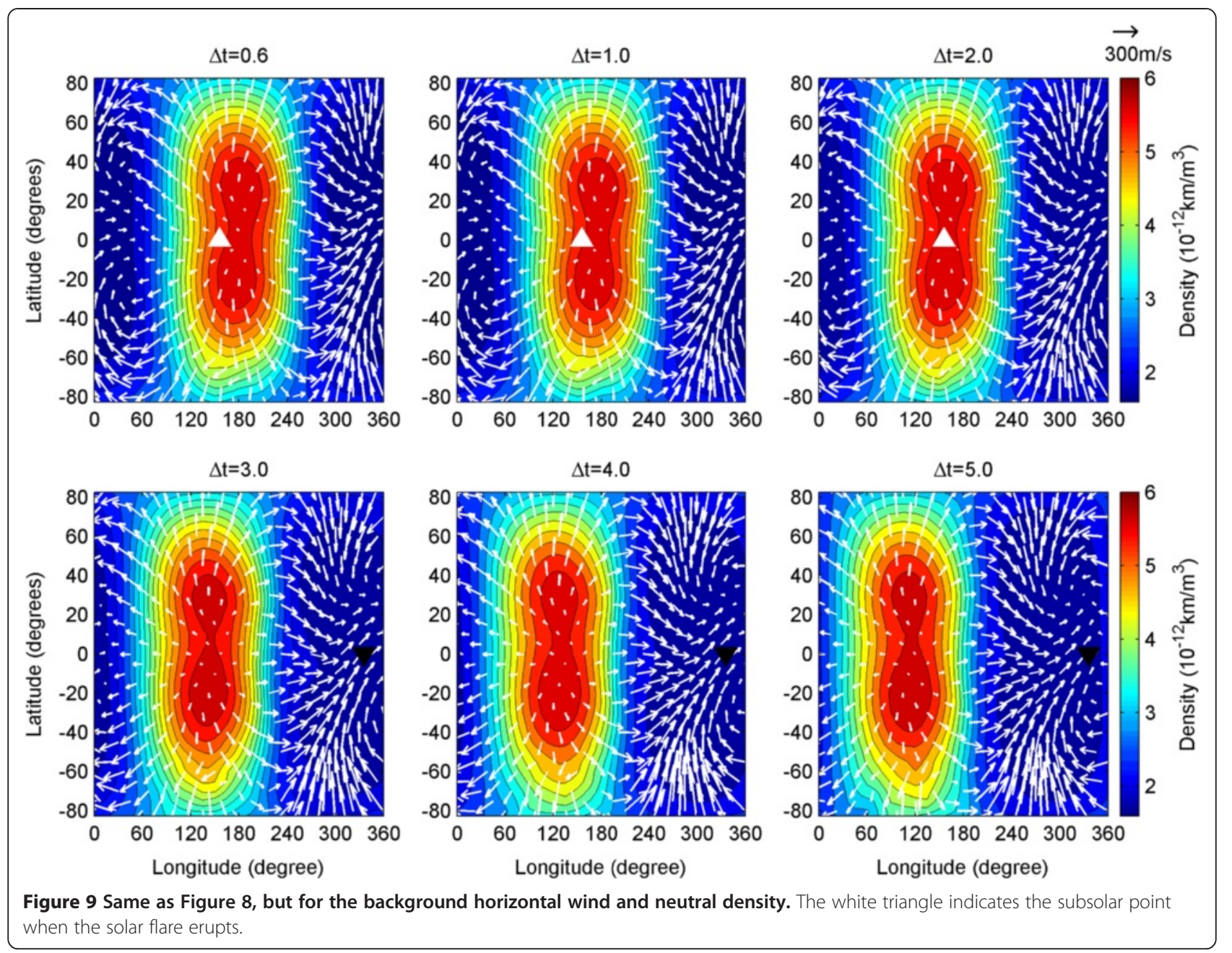

The height dependence of the thermospheric responses to a solar flare is shown in Figure 11. Left panels illustrate the neutral density and neutral temperature responses at the subsolar point. Right panels illustrate the corresponding response at the antisolar point. The results show that the percentage enhancement in neutral density increases with altitude for both the subsolar point in the dayside and the antisolar point in the nightside. There is a very small change of neutral density below $150 \mathrm{~km}$. The neutral density responses to the solar flare reach the peak almost at the same time $(\Delta t \approx$ $0.9 \mathrm{~h})$ for all altitudes. The results show that the enhancement in neutral temperature increases with altitude for the altitude range from 100 to $350 \mathrm{~km}$, but it has almost the same magnitude at altitudes of $350 \mathrm{~km}$ above. The height distribution of the increase in neutral temperature is similar with the temperature structure of the thermosphere.

It is well known that the ionospheric response to a solar flare is very fast because of the small time constant of electron and ions. The time and amplitude of the peak response are determined by peak solar irradiance (e.g., Afraimovich 2000; Zhang et al. 2002, 2011; Le et al. 2007). However, because of the large mass and high heat capacity in the thermosphere, the neutral gas response to a solar flare would be sluggish with regard to transient enhancement in solar EUV flux; that is, it needs longer time for neutral gas to react to the increase in solar EUV flux, and the neutral gas response also can last a longer time. Our simulations just show such a feature. For example, the percentage change of neutral density at subsolar point reaches the peak at $\Delta \mathrm{t} \approx 1 \mathrm{~h}$ when the EUV flux return to the normal level, and it takes as long as more than $20 \mathrm{~h}$ to return back to the background level.

Based on the analyses of the thermospheric response to all X-class solar flares during 2001 to 2006, Le et al. (2012) found that the thermospheric density enhancement is much more correlated with integrated EUV flux than with peak EUV flux, which suggests that the 


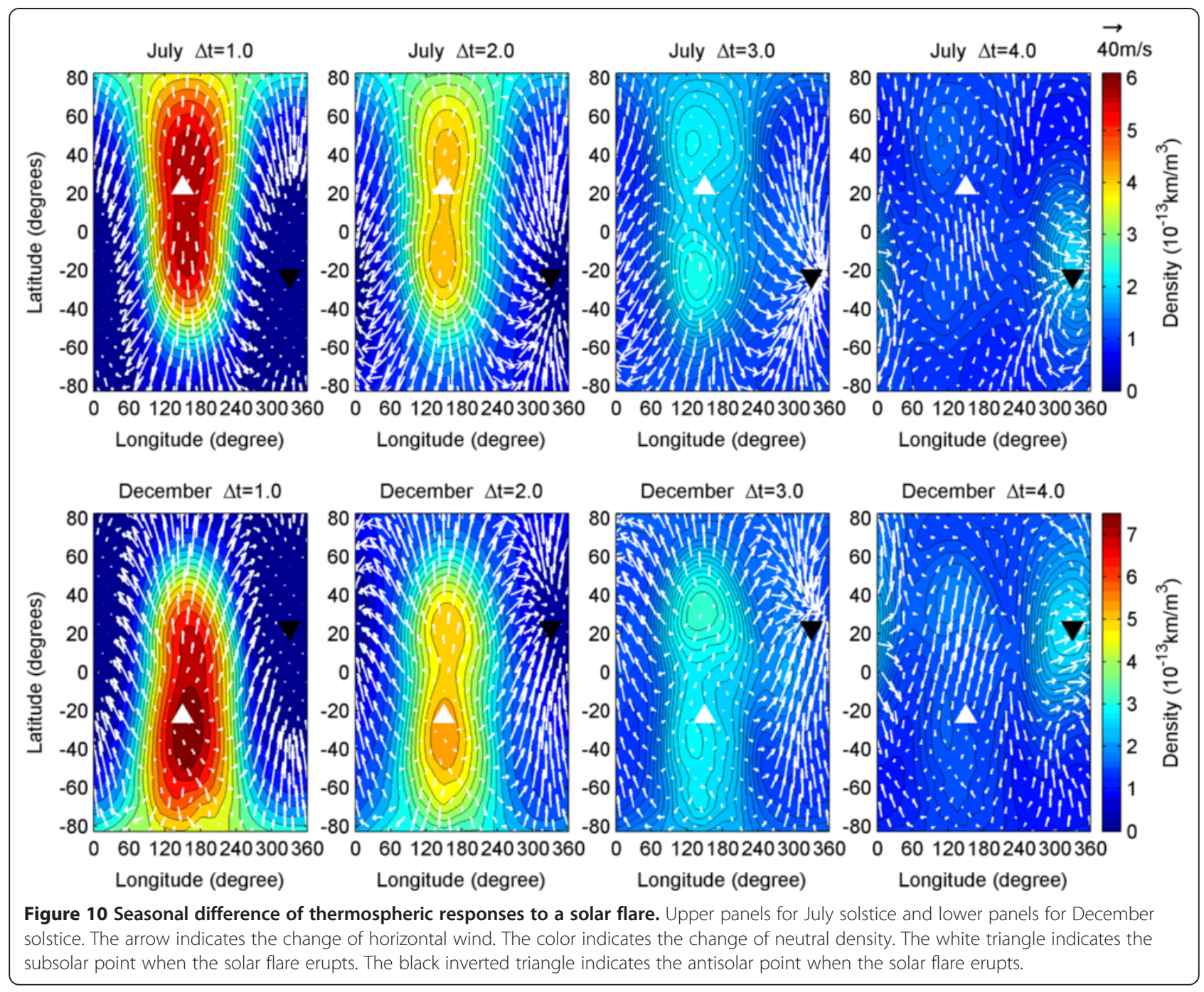

thermospheric response is strongly dependent on the total integrated energy into the thermosphere. Based on the simulations by the GITM, Pawlowski and Ridley (2011) also reported the same feature that the density response at $400 \mathrm{~km}$ altitude is dependent on the total integrated energy. To further verify the idea, we carried out other two simulations with the same peak solar EUV flux but different duration of EUV enhancement. For the first simulation, the solar flare duration is shortened by a half with the peak value unchanged. For the second one, the solar flare duration is lengthened by $100 \%$ with the peak value unchanged. Take the relative change of EUV $(\triangle \mathrm{EUV})$ at 30 to $35 \mathrm{~nm}$ during the solar flares as an example. The $\triangle \mathrm{EUV}$ is the ratio of the EUV during solar flare to the EUV before solar flare. The temporal of $\triangle E U V$ during the three solar flares (normal duration, double duration, and half duration) is illustrated in Figure 12a; that is, the first one has half integrated energy compared to the normal condition and the second one has the double integrated energy.

Figure 12b, c shows the dayside average responses of neutral density and neutral temperature to the three solar flares: half duration, normal duration, and double duration. The peak enhancement in the neutral density is $21.7 \%, 13.7 \%$, and $7.1 \%$ for the double duration flare, the normal flare, and the half duration flare, respectively. The peak increase in neutral temperature is $64.5,42.8$, and $22.2 \mathrm{~K}$ for the double duration flare, the normal flare, and the half duration flare, respectively. The results suggest that although with the same peak EUV flux, the larger integrated energy being deposited into the atmosphere results in the larger thermospheric responses. Pawlowski and Ridley (2011) reported a linear dependence of neutral density response on the total integrated energy. Our simulations show that is not a rigorous linear dependence between the density response and the 

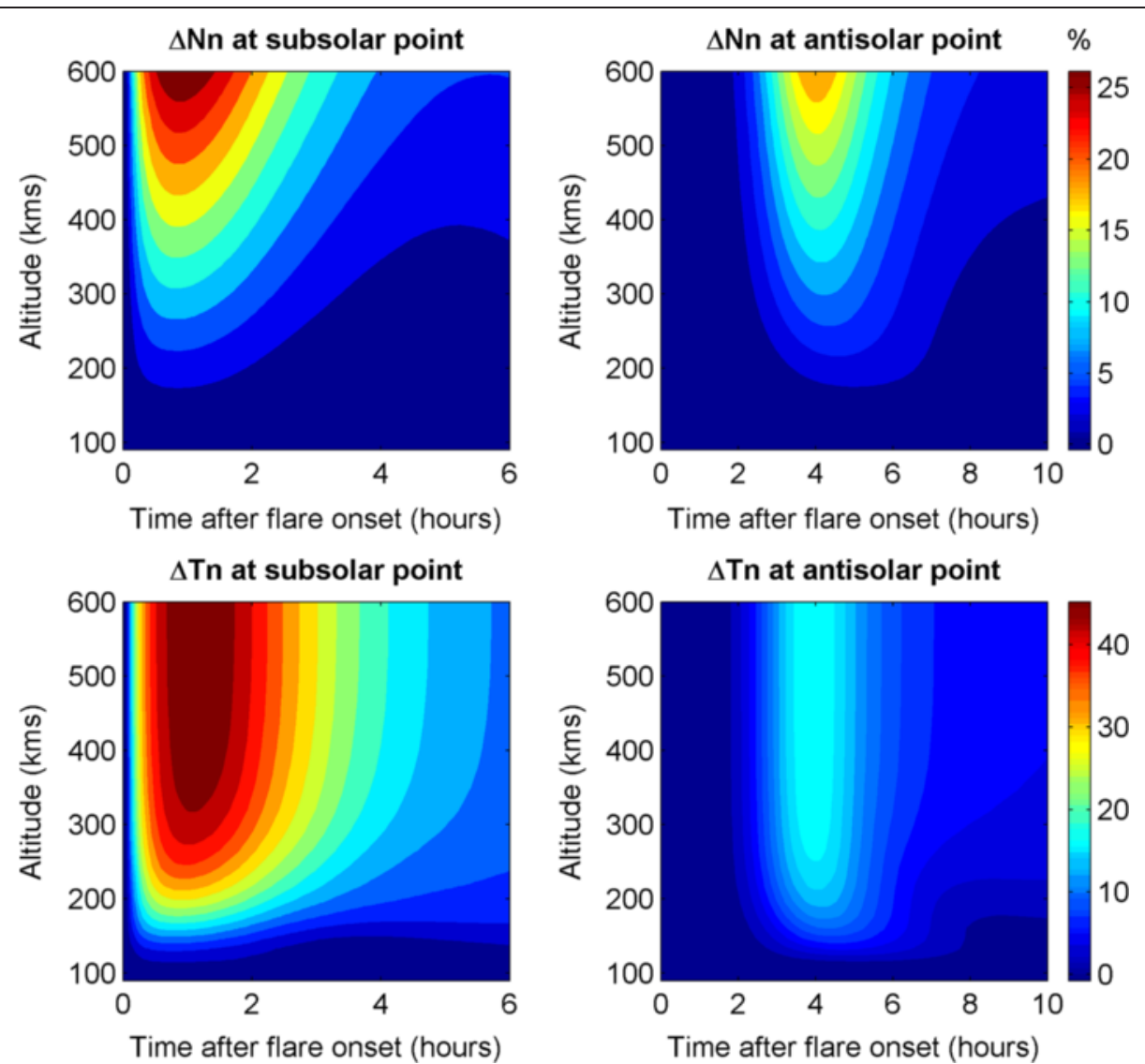

Figure 11 Height variation of neutral density and neutral temperature responses to a solar flare. Left panels for the subsolar point and right panels for the antisolar point.

total integrated energy. The peak enhancement in the neutral density does not increase by $100 \%$ but only increase by approximately $58 \%$ when the flare duration prolongs by $100 \%$ from the normal condition to double duration. These results show that the enhancement in neutral density increases nonlinearly with integral EUV flux. Its amplification decreases with integral EUV flux.

Figure 12 (normal duration lines) also illustrates the dayside average disturbance level of thermospheric density and temperature at $400 \mathrm{~km}$. The results show that there is a peak enhancement of about $13.7 \%$ in the global average neutral density at $400 \mathrm{~km}$ and a peak increase of about $42 \mathrm{~K}$ in the global average neutral temperature at $400 \mathrm{~km}$. It takes about $20 \mathrm{~h}$ for the density enhancement to drop to $1 \%$ and takes about $20 \mathrm{~h}$ for the temperature increase to drop to $2 \mathrm{~K}$. These results show that the thermospheric responses to a solar flare can last more than $20 \mathrm{~h}$, which is much longer than the ionospheric responses of which the typical duration is less than $2 \mathrm{~h}$ (Tsurutani 2005; Le et al. 2007).

To verify the simulated result of this study, the thermospheric density derived from the accelerometers on the CHAMP before and after the 6 April 2001 X5.6 solar flare is calculated. With a near-polar inclination, the satellite provides near-global coverage at an approximate altitude of $410 \mathrm{~km}$ within two local time sectors at most latitudes. All density data has been averaged into $3^{\circ}$ latitudinal bins to reduce any random errors. In addition, neutral density has also been normalized to a fixed height of $400 \mathrm{~km}$ using the NRL-MSISe-00 empirical density model. Figure 13 illustrates the temporal variation in the dayside sector (14.4 LT) and in the nightside sector (2.4 LT). The observed results show significant density increases in the dayside after the flare. The nightside observations also show some enhancements several hours after the flare. Figure 13 also shows that the enhancements in the dayside mainly appear in the middle-low latitudes. As for the nightside, the enhancements first appear in the high latitudes and then extend gradually to the middle and low latitudes. These temporal and spatial features are basically in agreement with the simulations mentioned above.

To further quantitatively compare the observations and the simulations, the latitude distributions of the 

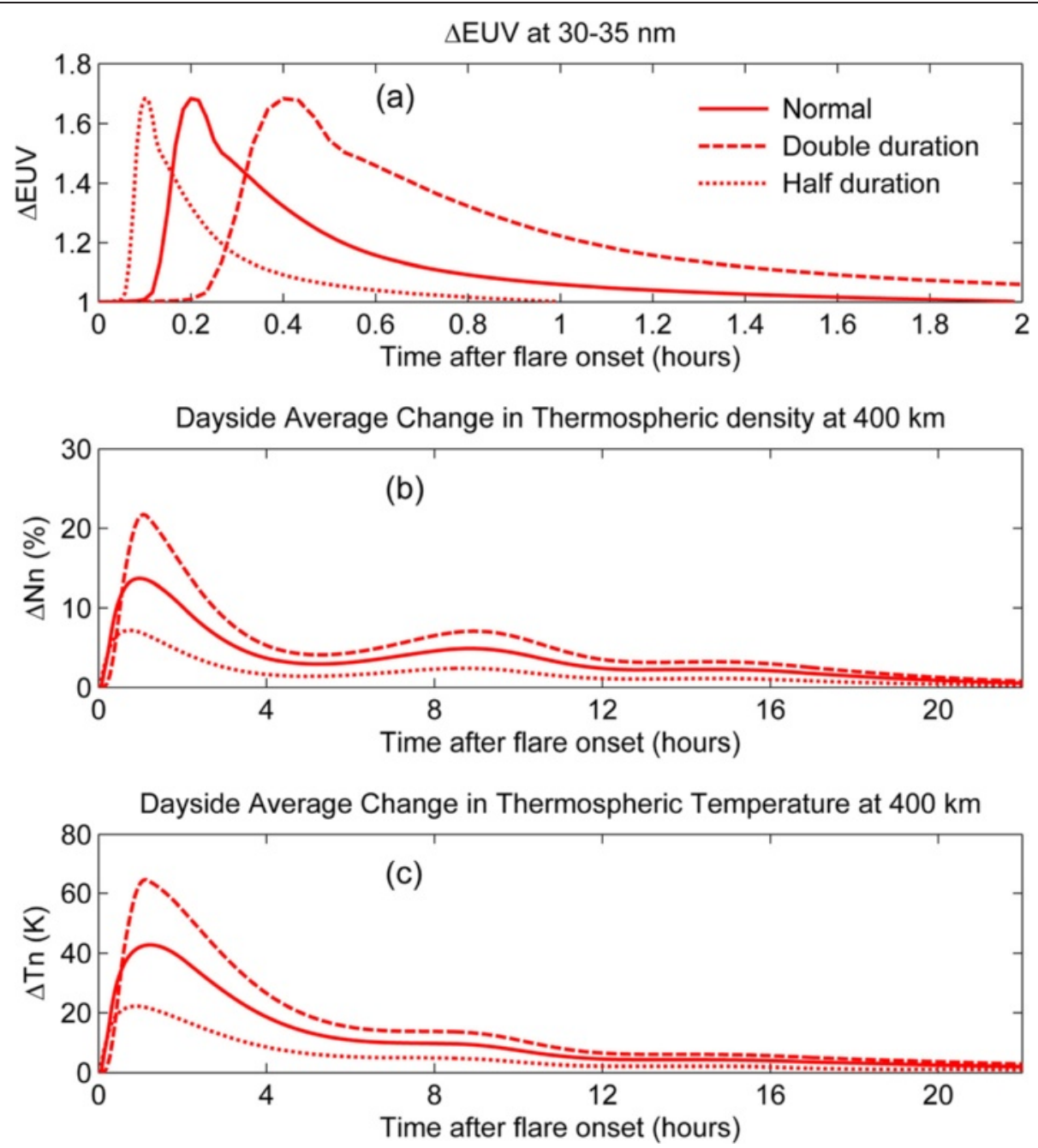

Figure 12 The relative change of EUV and dayside average change in the thermosphere. (a) The relative change of EUV at 30 to $35 \mathrm{~nm}$ during the solar flare. The solid line, the dashed line, and the dotted line refer to the EUV variation with normal duration, double duration, and dotted duration, respectively. Dayside average change in thermospheric density (b) and temperature (c) at $400 \mathrm{~km}$.

enhancements are calculated and shown in Figure 14. The mean of three orbits before the flare onset is calculated as the reference value. Thus, we can get the reference value at each latitude bin. To investigate the neutral density responses to solar flares in the dayside, the responses of the first three orbits (corresponding to the time within about $4 \mathrm{~h}$ ) after solar flare onset are calculated and their mean percentage change is taken as the response for the solar flare. As for the nightside, the mean percentage change within $8 \mathrm{~h}$ after the solar flare onset is calculated. The corresponding simulated results are also calculated. Both the observed results and simulated results are plotted in Figure 14. We can find that the simulated results are basically consistent with the observed results, although the observed results have larger latitudinal fluctuation. The comparison between the simulations and observations suggests that the GCITEM model can well model the thermospheric responses to a solar flare.

\section{Conclusions}

The thermospheric responses to a solar flare were investigated, based on the results of a modeling effort by the GCITEM model. The solar EUV variation during a solar flare is derived from the empirical model FISM. In this study, we did not model the thermospheric response to the great solar flare like the X17 solar flare on 28 October 2003, but modeled the effects of a weaker flare of X5. The simulated results show that there are significant enhancements in the neutral density and neutral temperature. The strongest responses of the thermosphere occur at the subsolar point. The larger solar zenith angle causes 


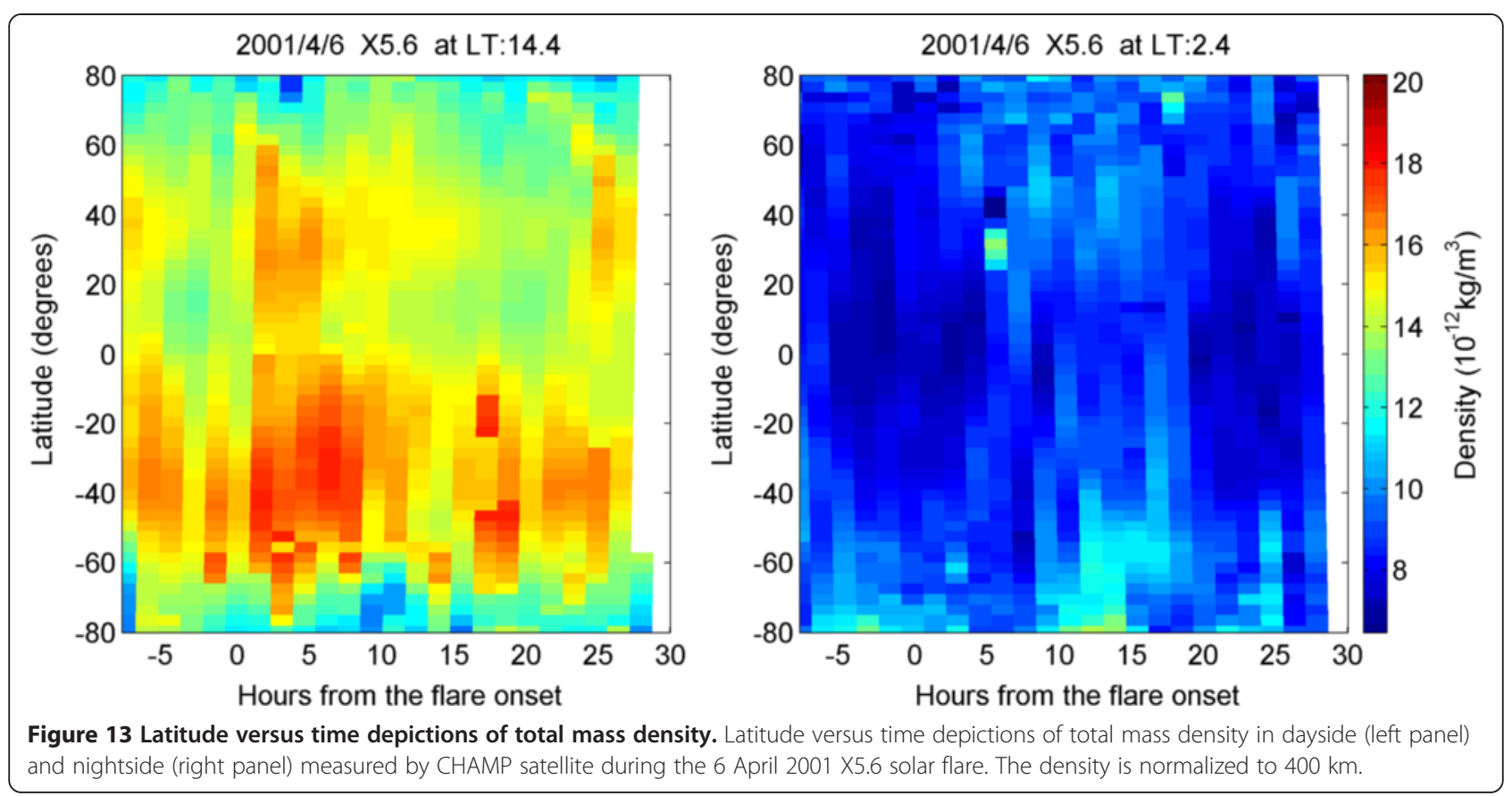

the smaller thermospheric responses, which suggests the strong effect of the solar zenith angle. The peak responses appear about $1 \mathrm{~h}$ after the solar flare onset for all latitudes. The thermospheric responses to a solar flare can last more than $20 \mathrm{~h}$.

In addition to the significant disturbances in the dayside, the simulated results also show that a solar flare can produce significant disturbance in the nightside. The percentage change of the neutral density in the nightside is just a little smaller than that in the dayside. There is a significant latitude dependence for nightside thermospheric response. It almost synchronizes with dayside in the polar region and high latitudes but is later at lower latitudes. The peak disturbance in the nightside appears at the antisolar point. The heating from the sudden increases in solar radiation during a solar flare disturbs the global thermosphere circulation, which results in the significant change in the horizontal wind. There is significant convergence process to the antisolar point, and thus the strong disturbances in the nightside occur at the antisolar point. The peak enhancement in the nightside appears about $4 \mathrm{~h}$ after the solar flare onset. In addition, our simulations show that although with the same peak EUV flux, the solar flare with longer duration would produce the stronger thermospheric response, which suggests that the integral energy during a solar
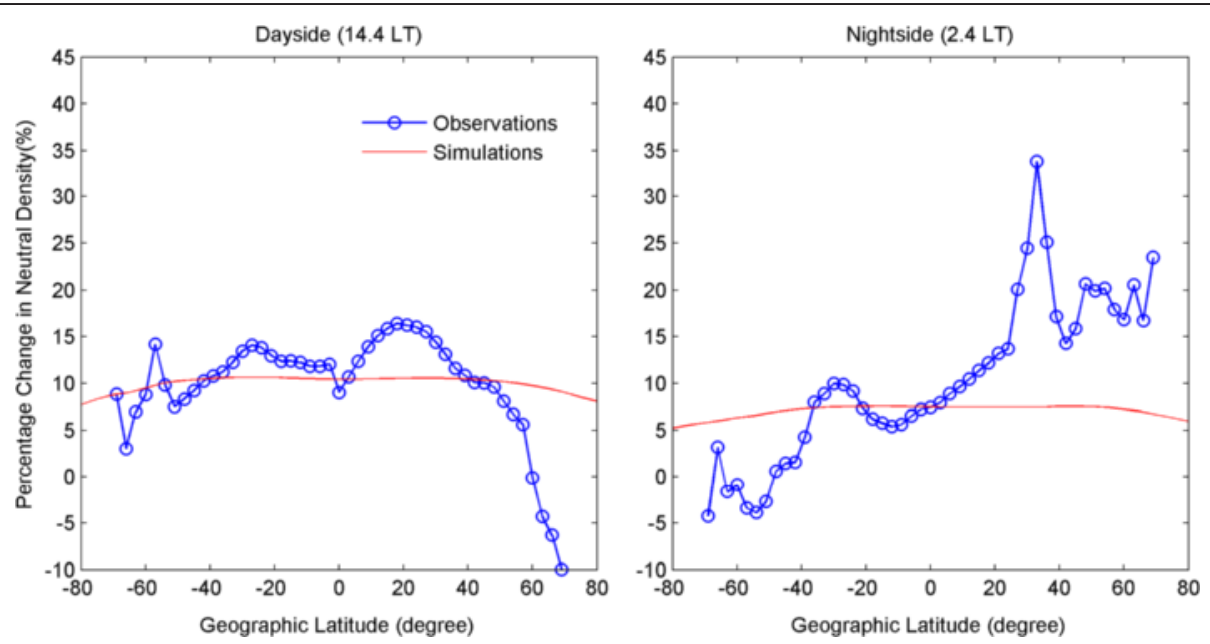

Figure 14 Latitudinal distribution of average change of neutral density at $\mathbf{4 0 0} \mathbf{~ k m}$. Left panel for dayside and right panel for nightside. Circle lines for the observations from CHAMP and solid lines for the simulations. For details of calculations of the percentage change, see the text. 
flare is an important factor of the thermospheric responses to a solar flare. To verify quantitatively the result of this modeling study, the simulated results are compared with the observations of neutral density derived from the accelerometers on the CHAMP satellite. The simulated results are basically consistent with the observed results, although the observed results have larger latitudinal fluctuation.

\section{Competing interests}

The authors declare that they have no competing interests.

\section{Authors' contributions}

$\mathrm{HL}$ planned and led the study, interpreted the results, and drafted the manuscript. ZR constructed the model for the simulations. YC, LL, and $H Z$ participated in the data analysis and interpretation. All authors read and approved the final manuscript.

\section{Acknowledgements}

This research was supported by the Chinese Academy of Sciences project (KZZD-EW-01-3), National Key Basic Research Program of China (2012CB825604), National Natural Science Foundation of China (41374162, 41231065, and 41321003).

Received: 5 September 2014 Accepted: 1 December 2014 Published online: 08 January 2015

\section{References}

Afraimovich EL (2000) GPS global detection of the ionospheric response to solar flares. Radio Sci 35(6):1417-1424. doi:10.1029/2000RS002340

Chamberlin PC, Woods TN, Eparvier FG (2007) Flare Irradiance Spectral Mode (FISM): daily component algorithms and results. Space Weather 5:S07005. doi:10.1029/2007SW000316

Chamberlin PC, Woods TN, Eparvier FG (2008) Flare Irradiance Spectral Model (FISM): flare component algorithms and results. Space Weather 6:S05001. doi:10.1029/2007SW000372

Forbes JM, Lu G, Bruinsma S, Nerem S, Zhang X (2005) Thermosphere density variations due to the 15-24 April 2002 solar events from CHAMP/STAR accelerometer measurements. J Geophys Res 110:A12S27. doi:10.1029/2004JA010856

Le H, Liu L, Chen B, Lei J, Yue X, Wan W (2007) Modeling the responses of the middle latitude ionosphere to solar flares. J Atmos Solar Terr Phys 69:1587-1598. doi:10.1016/j.jastp.2007.06.005

Le H, Liu L, He H, Wan W (2011) Statistical analysis of solar EUV and X-ray flux enhancements induced by solar flares and its implication to upper atmosphere. J Geophys Res 116, A11301. doi:10.1029/2011JA016704

Le H, Liu L, Wan W (2012) An analysis of thermospheric density response to solar flares during 2001-2006. J Geophys Res 117:A03307. doi:10.1029/2011JA017214

Le H, Liu L, Chen Y, Wan W (2013) Statistical analysis of ionospheric responses to solar flares in the solar cycle 23. J Geophys Res Space Physics 118:576-582. doi:10.1029/2012JA017934

Leonovich LA, Afraimovich EL, Romanova EB, Taschilin AV (2002) Estimating the contribution from different ionospheric regions to the TEC response to the solar flares using data from the international GPS network. Ann Geophys 20:1935-1941. doi:10.5194/angeo-20-1935-2002

Liu JY, Lin CH, Tsai HF, Liou YA (2004) lonospheric solar flare effects monitored by the ground-based GPS receivers: theory and observation. J Geophys Res 109:A01307. doi:10.1029/2003JA00993

Liu JY, Lin CH, Chen YI, Lin YC, Fang TW, Chen CH, Chen YC, Hwang JJ (2006) Solar flare signatures of the ionospheric GPS total electron content. J Geophys Res 111:A05308. doi:10.1029/2005JA011306

Liu H, Lühr H, Watanabe S, Ko"hler W, Manoj C (2007) Contrasting behavior of the thermosphere and ionosphere in response to the 28 October 2003 solar flare. J Geophys Res 112:A07305. doi:10.1029/2007JA012313

Liu L, Wan W, Chen Y, Le H (2011) Solar activity effects of the ionosphere: a brief review. Chin Sci Bull 56(12):1202-1211. doi:10.1007/s11434-010-4226-9
Mahajan KK, Lodhi NK, Upadhayaya AK (2010) Observations of X-ray and EUV fluxes during $\mathrm{X}$-class solar flares and response of upper ionosphere. J Geophys Res 115:A12330. doi:10.1029/2010JA015576

Pawlowski DJ, Ridley AJ (2008) Modeling the thermospheric response to solar flares. J Geophys Res 113:A10309. doi:10.1029/2008JA013182

Pawlowski DJ, Ridley AJ (2009) Modeling the ionospheric response to the 28 October 2003 solar flare due to coupling with the thermosphere. Radio Sci 44:RSOA23. doi:10.1029/2008RS004081

Pawlowski DJ, Ridley AJ (2011) The effects of different solar flare characteristics on the global thermosphere. J Atmos Terr Phys 73:1840-1848. doi:10.1016/j.jastp.2011.04.004

Qian L, Burns AG, Chamberlin PC, Solomon SC (2010) Flare location on the solar disk: modeling the thermosphere and ionosphere response. J Geophys Res 115:A09311. doi:10.1029/2009JA015225

Ren Z, Wan W, Liu L (2009) GCITEM-IGGCAS: a new global coupled ionospherethermosphere-electrodynamics model. J Atmos Sol Terr Phys 71 (17\&18):2064-2076

Schunk RW, Nagy AF (2000) lonospheres: physics, plasma physics, and chemistry Cambridge Atmos Space Sci Ser 59

Sutton EK, Forbes JM, Nerem RS, Woods TN (2006) Neutral density response to the solar flares of October and November, 2003. Geophys Res Lett 33:L22101. doi:10.1029/2006GL027737

Tsurutani BT (2005) The October 28, 2003 extreme EUV solar flare and resultant extreme ionospheric effects: comparison to other Halloween events and the Bastille Day event. Geophys Res Lett 32:L03S09. doi:10.1029/2004GL021475

Wan W, Liu L, Yuan H, Ning B, Zhang S (2005) The GPS measured SITEC caused by the very intense solar flare on July 14, 2000. Adv Space Res 36:2465-2469. doi:10.1016/.asr.2004.01.027

Zhang DH, Xiao Z (2005) Study of ionospheric response to the $4 \mathrm{~B}$ flare on 28 October 2003 using international GPS service network data. J Geophys Res 110:A03307. doi:10.1029/2004JA010738

Zhang DH, Xiao Z, Chang Q (2002) The correlation of flare's location on solar disc and the sudden increase of total electron content. Chin Sci Bull 47(1):82-85

Zhang DH, Mo XH, Cai L, Zhang W, Feng M, Hao YQ, Xiao Z (2011) Impact factor for the ionospheric TEC response to solar flare irradiation. J Geophys Res 116:A04311. doi:10.1029/2010JA016089

\section{Submit your manuscript to a SpringerOpen ${ }^{\circ}$ journal and benefit from:}

- Convenient online submission

Rigorous peer review

- Immediate publication on acceptance

- Open access: articles freely available online

- High visibility within the field

- Retaining the copyright to your article

Submit your next manuscript at $>$ springeropen.com 